FOUNDATIONS OF COMPUTING AND DECISION SCIENCES Vol. 40

\title{
THE APPLICABILITY OF SWE IN POLISH SPATIAL DATA INFRASTRUCTURES - THE EXAMPLE OF THE SENSORML LANGUAGE
}

\author{
Maciej ROSSA, Mariusz ROGULSKI ${ }^{1}$
}

\begin{abstract}
Mobile and stationary sensors currently used to measure various environmental parameters, functioning independently or as part of monitoring networks and measurement stations, provide vast amounts of data on the state and quality of the environment on the Earth. If the data is to be used effectively, they must be exchanged and shared among IT systems. Systems which offer services of searching, exchange, sharing, visualisation and analysis of dispersed and varied data resources on the widely understood environment are, for example, spatial data infrastructures.

The article presents an overview of IT technologies and standards which offer interoperability in spatial data infrastructures. It first defines interoperability and then describes the most important issues connected with spatial data infrastructures on the example of INSPIRE. An example standard which facilitates interoperability in INSPIRE is the SensorML language, a component of Sensor Web Enablement (SWE). Its practical application is proposed - for description of processes of air monitoring in a spatial data infrastructure that is an element of the Polish national environmental monitoring plan.
\end{abstract}

Keywords: Spatial Data Infrastructures, SensorML, INSPIRE

\section{Introduction}

At present, globally, there are hundreds of thousands mobile and stationary sensors, which measure various environmental parameters and function independently or are part of thousands of monitoring networks and measurement stations that monitor all elements of the environment. Additionally, over 50 environment satellites carry out their research missions. Various observations and measurements are also made all the time, both in the field and in laboratories. These activities generate an unimaginable amount of data on the

${ }^{1}$ Mariusz.Rogulski@is.pw.edu.pl; Maciej.Rossa@is.pw.edu.pl, Warsaw University of Technology, Faculty of Environmental Engineering, Department of Information Science and Environment Quality Research, Nowowiejska 20, 00-653 Warsaw 
state and quality of the environment on the Earth and provide new information non-stop and to an extent greater than ever before.

In order to be able to fully use these vast and varied resources, it is necessary to provide the possibility of their exchange and sharing among different IT systems. Technological progress connected with the development of the internet has contributed to improvement of the functions of searching, exchanging, sharing, visualisation and analysis of dispersed and varied information resources on the widely understood environment. An example of such implementation is SDI - spatial data infrastructures with geostandards as the basis of their functioning [28].

Spatial data infrastructures include spatial data, as well as services, technical means, processes and procedures connected with them. Spatial data is information on the location (determined using coordinates in a given system of reference), geometrical properties and spatial relations of objects which may be identified with reference to the Earth.

The aim of this publication is an overview of IT technologies and standards which facilitate interoperability in spatial data infrastructures, presentation of a component of Sensor Web Enablement - a specification of SensorML, as an example of a language which supports interoperability and proposition of its use in a spatial data infrastructure in Poland.

Section 2 presents the concept of interoperability. Section 3 is an introduction to the subject of spatial data infrastructures. Development of the concept in connection with interoperability on the example of INSPIRE is presented in section 4. Section 5 describes the SensorML language as an example of a standard supporting interoperability in INSPIRE. A practical application of the language with a suggestion of its use in a spatial data infrastructure in Poland is presented in section 6. The last section contains a summary.

\section{Interoperability}

The possibility of exchanging, sharing and automatic processing of data in IT systems is connected with their interoperability, which may be discussed in the context of interoperability of data and services.

The concept of interoperability is closely linked with informatics and with IT systems in particular. Interoperability is generally described as “...the ability of two or more systems or components to exchange information and to use the information that has been exchanged..." [14]. More precisely, the concept may be defined as "...capability to communicate, execute programs, or transfer data among various functional units in a manner that requires the user to have little or no knowledge of the unique characteristics of those units..." [16]. Paraphrasing [21], achieving interoperability is the condition which enables communication among systems and exchanging and using the same data in different systems.

Most systems or ways of categorisation of interoperability [10, 13, 15, 20] distinguish its three main levels:

- formal and organisational - formal and legal aspects, legal regulations, structures, processes and procedures. This level is sometimes divided into two separate levels: the legal one and the organisational one. This is mainly applied when analysing interoperability in the context of tasks realised by state administration units; 
- $\quad$ technical, which includes three more specific levels (Fig. 1):

o systemic - tools, operation systems, transmission protocols, service security, data services;

o syntactic - formats and standards of data exchange on the abstract level (languages of data exchange which only have syntactic standardisation);

o schematic - schemata of data exchange and presentation (domain languages of data exchange);

- $\quad$ semantic - correct, unambiguous understanding of the exchanged and shared information by all its users-agents (both IT systems and people).

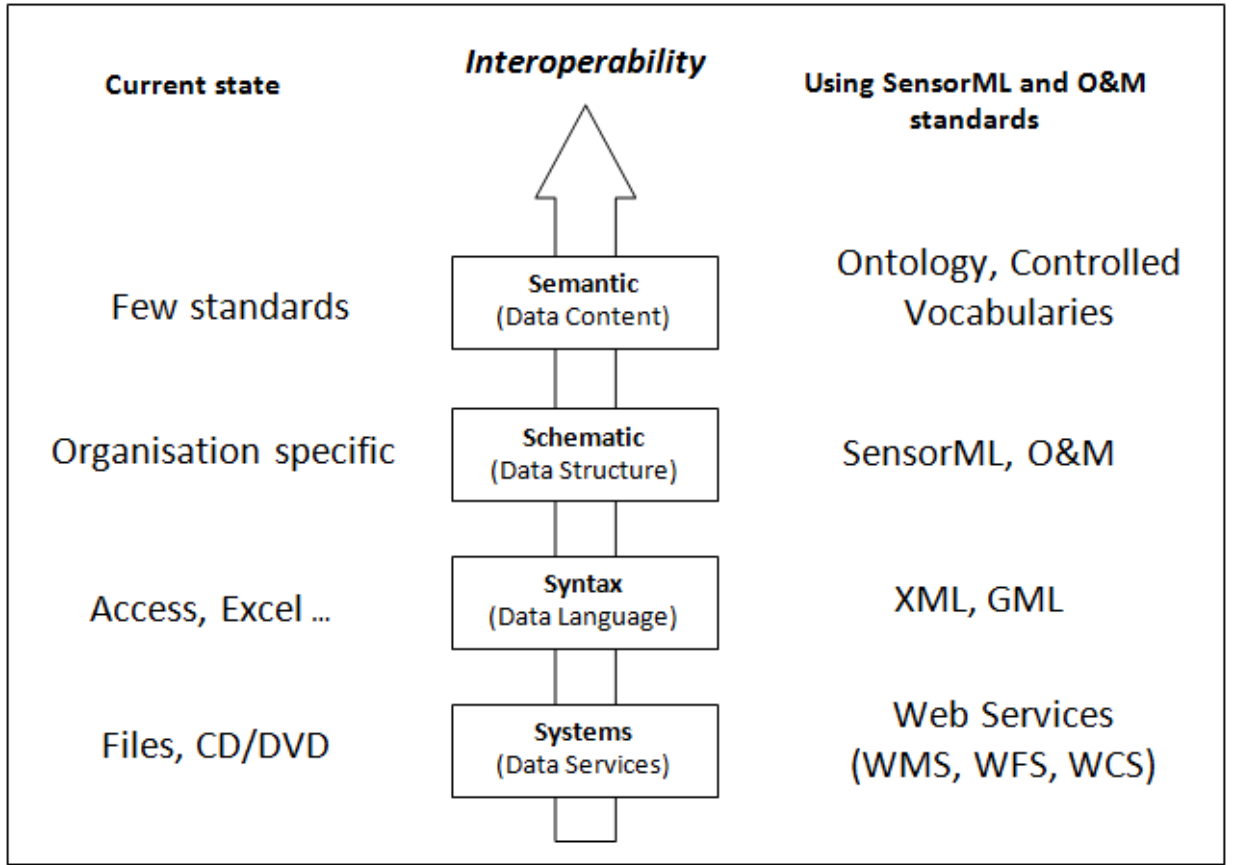

Figure 1. Levels of technical interoperability (according to GeoSciML - modified and complemented)

Activities aimed at achieving interoperability at the formal and organisational and technical levels have for a long time been effectively solved, implemented and realised. Great advances in this area are also visible in the fields connected with environmental studies, i.e. geology, hydrogeology, oceanography and meteorology [24, 29, 30, 31]. However, semantic interoperability is still being developed. Despite constant development of the capabilities of network resources to communicate, especially the development of web services, the issue is still unresolved and needs further research and analyses [21]. An example of the solutions suggested so far may be the use of methods based on ontologies and inference in the project meanInGs [23]. 


\section{Spatial data infrastructures}

A way of supporting interoperability is processing data in unambiguously defined, strict schemata published in specialised web services which have individual communication protocols. This concept for spatial data is used in spatial data infrastructures (SDI), which are built on the basis of SOA (Service Oriented Architecture) using web service technologies [26]. To some extent, using SDI allows to automate the use of processed metadata and spatial data $[17,18,19]$. An example of practical realisation of this model is INSPIRE - Infrastructure for Spatial Information in the European Community, which comprises SDIs of EU member countries, also the Polish national spatial data infrastructure (IIP). An example of SDI implementation using SOA is the EU system BRISEIDE (BRIdging SErvices, Information and Data for Europe) [27].

Essential for interoperability in SDI, also in INSPIRE and IIP, are geostandards and norms provided by two standardisation organisations: OGC (Open Geospatial Consortium, an organisation that creates and implements open standards for spatial data and services, geographical data systems, for processing data) and ISO (International Organisation for Standardisation). They form the basis for construction and functioning of SDI, supporting full technical interoperability, both in terms of service communication and data exchange [28]. A growing number of data and services entails the necessity to use more and more advanced IT tools and technologies. The possibilities and perspectives of development in this field using i.a. cloud services, as well as grid technology are described in [12] on the example of a project of the European Commission "enviroGRIDS". In [11] there is a suggestion of enhancing standard cataloguing services in SDI with semantic elements, while in [9] - a semantic development of cataloguing services in SDI for a region in Italy.

\section{Interoperability in SDI on the example of INSPIRE}

\subsection{Formal and organisational interoperability}

Interoperability at the formal and organisational level in INSPIRE is realised through a wide range of formal and legal solutions (procedural and organisational ones), the aim of which is to ensure cooperation of all those involved in creating and processing spatial data included in INSPIRE. These issues are regulated by appropriate legislation (the INSPIRE Directive implemented through the Polish SDI act) and executive regulations (EU regulations - which are binding and do not need to be implemented in national legislation), as well as technical implementation specifications (http://inspire.ec.europe.eu).

\subsection{Technical interoperability}

Technical interoperability in spatial data infrastructures, both in terms of services and data, is effected through implementation of OGC geostandards and ISO 19100 norms; in the case of INSPIRE also through dedicated technical guidelines. 
The foundation of technical syntactic implementation is the GML language (Geography Markup Language), which is an application of the XML language. It is an XML grammar for expressing geographical features and their relations. In simple terms, GML describes only their geometry and topology but not their meaning. It contains generic geographical data that contain points, curves, polygons etc., but not for example, stream gauges, transport routes or borders of cadastre plots [24].

For the purposes of data exchange within a field of knowledge and for support of interoperability at the technical schematic level, on the basis of the GML language, field dedicated languages of data exchange (not formats) are developed and they are its profiles (simplification) or applications (extension) [25]. So far, over 20 different field data exchange languages have been developed, which are application schema or GML profiles (http://www.ogcnetwork.net/gmlprofiles), and work is still being done on new ones.

The above standards are the basis for creation of other languages of data exchange dedicated to various fields. At present, there are over twenty languages of this type in the fields of: Earth sciences (geology, tectonics, hydrogeology, hydrology, soil science), spatial planning, geohazards, agriculture, meteorology and climatology, hydrography and oceanography, and biology. Moreover, there is a group of application schema and GML profiles predefined for 34 subjects of INSPIRE spatial data. In some cases (geology, soil science, mineral resources, hydrology), INSPIRE data exchange languages are equivalent to OGC standards. Examples of this type of language include GeoSciML (GeoScience Markup Language) - a more advanced language of this type, GWML (Ground Water Markup Language), AgriXchange (a GML application scheme for description of spatial data on INSPIRE subjects connected with agriculture) [29].

It is worth noting that all the above mentioned data exchange languages share general and field classes of objects, e.g. some classes of objects of the GeoSciML language, describing geological age, mineral composition of rocks or geological structures, inherited to the ResourceML language predefined to the INSPIRE subject "natural resources" [30, 31].

Moreover, each language describing spatial data on the state and quality of the environment, has inheritable classes of objects from two base standards: SensorML and Observations and Measurements (O\&M) - data exchange schemata on measurements and observations, their results, procedures and methodologies ${ }^{2}$.

In INSPIRE ${ }^{3}$, only a few subjects of spatial data include data on the state and quality of the environment which are derived directly from measurements and observations. These subjects include:

- hydrography;

- geology (with hydrogeology);

- $\quad$ soil - soils and subsoil characterised according to depth, texture, structure and content of particles and organic material, stoniness, erosion, where appropriate mean slope and anticipated water storage capacity;

- production and industrial facilities - industrial production sites, including installations covered by Council Directive 96/61/EC of 24 September 1996 concerning integrated pollution prevention and control (1) and water abstraction facilities, mining, storage sites.

\footnotetext{
${ }^{2}$ http://www.opengeospatial.org/standards/om

${ }^{3}$ http://inspire.ec.europa.eu
} 
- $\quad$ natural risk zones - vulnerable areas characterised according to natural hazards (all atmospheric, hydrologic, seismic, volcanic and wildfire phenomena that, because of their location, severity, and frequency, have the potential to seriously affect society), e.g. floods, landslides and subsidence, avalanches, forest fires, earthquakes, volcanic eruptions.

- environmental monitoring facilities - location and operation of environmental monitoring facilities includes observation and measurement of emissions, of the state of environmental media and of other ecosystem parameters (biodiversity, ecological conditions of vegetation, etc.) by or on behalf of public authorities.

- atmospheric conditions - physical conditions in the atmosphere. Includes spatial data based on measurements, on models or on a combination thereof and includes measurement locations.

- meteorological geographical features - weather conditions and their measurements; precipitation, temperature, evapotranspiration, wind speed and direction.

- $\quad$ oceanographic geographical features - physical conditions of oceans (currents, salinity, wave heights, etc.).

- human health and safety - geographical distribution of dominance of pathologies (allergies, cancers, respiratory diseases, etc.), information indicating the effect on health (biomarkers, decline of fertility, epidemics) or well-being of humans (fatigue, stress, etc.) linked directly (air pollution, chemicals, depletion of the ozone layer, noise, etc.) or indirectly (food, genetically modified organisms, etc.) to the quality of the environment.

To ensure technical interoperability in INSPIRE, chosen inherited classes of objects from SensorML and O\&M standards have been implemented for the above listed subjects.

\section{SensorML}

SensorML is an XML schema used to describe a model of functioning of sensors and measurement processes connected with them. With the use of SensorML, one can describe a wide range of sensors, both mobile and stationary ones, those taking measurements on site or remotely. In addition, it allows to, for instance, describe algorithms needed to control sensors, localise observations made with sensors, and process them at a low level. Sensors covered by SensorML include: stationary ones measuring on site, e.g. metanometer, thermometer, gravimeter; stationary ones measuring remotely, e.g. Lidar, Doppler radar; mobile ones measuring on site, e.g. sensors for measurement of the ozone layer on aircraft, GPS devices; mobile ones measuring remotely, e.g. cameras for air photos, satellite scanners. Uniform encoding benefits the integration of heterogeneous sensors as it provides a standard view to the user.

The language is a component created by OGC as part of the specification Sensor Web Enablement (SWE) and the system Sensor Web [22]. Thus, some of its parts are connected or enable reference to other elements of the project. An example may be the possibility to package the data from the sensor or process to an object in a format available in O\&M. 
SensorML is an approved OGC standard. The latest version (SensorML 2.0) was approved on 2013-12-10.

A basic element of the language is a measurement process for which it is possible to determine input, output, parameters and additional information characterising the process. The user may create many types of processes concerning any environmental component, which as their basis require attributes defined in the base process. Processes may be both physical processes connected with measurements and observations, and processes other than physical ones (e.g. software processes connected with processing measured quantities or modelling).

The most important abstract types of objects offered by SensorML 2.0, which at the same time allow to use a dialect, include:

- ObservableProperty - represents physical parameters of the observed and/or measured phenomenon. Parameters include, for instance, temperature, gravitational force, location, chemical concentration etc. Objects inheriting from this type may also describe quantities connected with phenomena which have been determined in other ways than direct measurement (e.g. as a result of modelling).

- DescribedObject - an abstract class processing metadata for other classes of processes. These include many descriptive properties on general process information (e.g. keywords, classifications), limitations (e.g. timeframe, security limitations, legal limitations), classifications (properties and possibilities), references (contacts and documentation) and history. They are grouped in lists for simpler analysis.

- AbstractProcess - a basic abstract class inheriting from DescribedObject, which additionally offers properties connected with input, output and process parameters, process use, and the possibility of further (descriptive, for instance) development of derived processes.

On the basis of abstract classes, SensorML also has additional classes:

- $\quad$ Simple Process - for indivisible processes, i.e. those the realisation of which is treated as a whole. The class also has properties which enable provision of the methodology used in the process.

- Aggregate Process - for complex, multiple-component processes, with the possibility of mapping flow of data between the components,

- Physical Component - represents real facilities for which it is essential to define spatial and time coordinates,

- Physical System - used to model physical facilities as processes for which location in the real world is known and significant,

- Processes with Advanced Data Types - a class offering support for more advanced types of data than those offered by the abstract class AbstractProcess (e.g. DataArray, Matrix, DataStream and Choice).

SensorML 2.0 is strongly related to GML3.2, because all elements are substitutable for GML AbstractValue and AbstractFeature. For example, DescribedObject is derived from GML AbstractFeature.

Complementation and support of the SensorML language is offered in two other standards - Sensor Observation Service (SOS) and Sensor Planning Service (SPS). Both have been defined as interfaces so they may be used to create web services, for instance. 
The functionality of SOS is mainly provision of interface enabling access to observations made with measurement sensors and to sensor description. Offered classes and methods enable, i.a. registration and deletion of sensors, as well as addition, deletion and browsing of existing observations.

The SPS standard is devoted to control of sensors and measuring devices. For example, it allows to describe and download sensor parameters, send requests to sensors at different stages of their operation (e.g. planning, data gathering, archiving etc.), to reserve resources to complete the planned tasks. In contrast to SOS, it does not offer access to data collected with sensors but only offers the possibility to parameterise sensors and measuring devices.

Apart from these, the SWE specification also includes:

- Sensor Alert Service (SAS) - a web service specification which allows to obtain and process data from sensors,

- Web Notification Service (WNS) - a web service specification for registration of users and groups of users and for sending messages to them using various communication protocols,

- Observations and Measurements Schema (O\&M) - an international standard which defines a conceptual schema encoding for observations and measurements, and for features involved in sampling when making observations.

While the O\&M standard was developed in the context of geographic information, it is not limited to spatial data. XML encoding in O\&M is very general since the result of observations or measurements may be "packed" in any structure described in the XML format. O\&M is one of the core standards in OGC.

There may be a relation between SensorML objects and O\&M objects. Usually an observation (encoded in O\&M) has a relationship to a procedure representing the process (encoded in SensorML) which has performed the observation. Therefore, SensorML and O\&M together can be used to support different aspect of measurements. Data in SensorML can be used for discovery of context sensor, while data in O\&M - to support the mapping of sensor observations into an application and user level.

\section{Possibilities of practical application of the SensorML language in Poland}

Examples of application of the SWE standard along with a short description of services included in the specification may be found in [5]. Presented examples of practical implementations include: NASA-sponsored Land Information Sensor Web, The Sensors Anywhere (a European Commission project), or a German-Indonesian tsunami early warning system.

In [3], the authors have described the uses of SWE (also of SensorML) to create a web cataloguing service based on an OGC cataloguing service, enabling localisation, access, parameters provisioning and use of sensors and algorithms describing sensors. A proposed concept also includes development of a dictionary of business transactions ebXML. Technologies and standards included in SWE have also been used to create a phenomenonbased service of obtaining spatial data on demand. In the proposed service, the user may 
define criteria of data and when they become available (e.g. as a result of making a measurement), they are instantly sent to the user [8].

In turn, [2] proposes using BPEL and process chains from SensorML, a method of creating workflows for the so-called e-science - for these areas of science that require calculations in heavily dispersed network environments or that use vast amounts of data processed in grid environments.

SensorML is not the only language for standardisation of processes connected with functioning of sensors. An overview of currently developed norms and standards may be found in [32]. The authors present there, for example, standards created by ISO (ISO/IEC 18000 norm), IEEE (IEEE 1451) and the mentioned earlier standards created by OGC which are part of SWE. They also point to cooperation possibilities between these units and perspectives of development of standards. [4] presents SSN ontology created by Semantic Sensor Network Incubator Group, which describes sensors in terms of their possibilities, measurement processes and conducted observations. The ontology includes significant parts of SensorML and O\&M languages.

In Poland, the described standards have not been widely used yet. They could be used when observations are made with different devices and methods and the process of collecting and processing a large number of measurements is quite developed. A good example application would be for description of processes of air monitoring. The reason is a big number of varied measuring devices and measured indicators of air quality, as well as quite a developed process of verification, analysis and processing of the data.

Air monitoring is a process conducted by voivodship inspectorates for environmental protection as part of the national environmental monitoring plan (NEMP). The obligation and its extent is defined in the act Environmental Protection Law (art. 25-29) [1]. In accordance with the act, the aim of NEMP is support for environmental actions through systematic information of administration units and the society on, e.g., the quality of natural elements, changes in the quality of natural elements and the reasons for them. The monitoring obligation for the Inspection of Environmental Protection is laid down in the Act on National Environmental Inspection.

At present, results of measurements of air pollution concentrations from automatic stations (in some cases, along with accompanying meteorological parameters) are automatically transmitted via a telecommunications network to databases maintained by voivodship inspectorates for environmental protection. These systems also receive measurement results made with non-automatic methods. Verified data is used to: create and update reports from special zones, where there is a risk of exceeding warning levels of air pollution concentrations, to develop short-term forecasts of air quality in special zones, to create reports (e.g. on the state of the environment), etc. The data is also available to the society.

Currently, all 16 voivodship inspectorates present results from stations of automatic air monitoring in the voivodship (on-line, on their websites). In all cases, the data is presented in the form of a static table on the website, sometimes supported with a presentation of the measurement results on a graph (graphs). This is usually effected in two forms - it is either possible to generate a graph for all parameters of a station or for a chosen parameter for all stations (e.g. in the Szczecin inspectorate), or it is possible to choose from a list of parameters on one's own and compare them for different measurement stations. It is impossible to generate graphs in the case of Warmińsko-mazurskie, Lubuskie and Silesian 
inspectorates. Websites of a few inspectorates (Małopolskie, Wielkopolskie, Lubuskie and Opole) are based on the same pattern (Fig. 2-3).

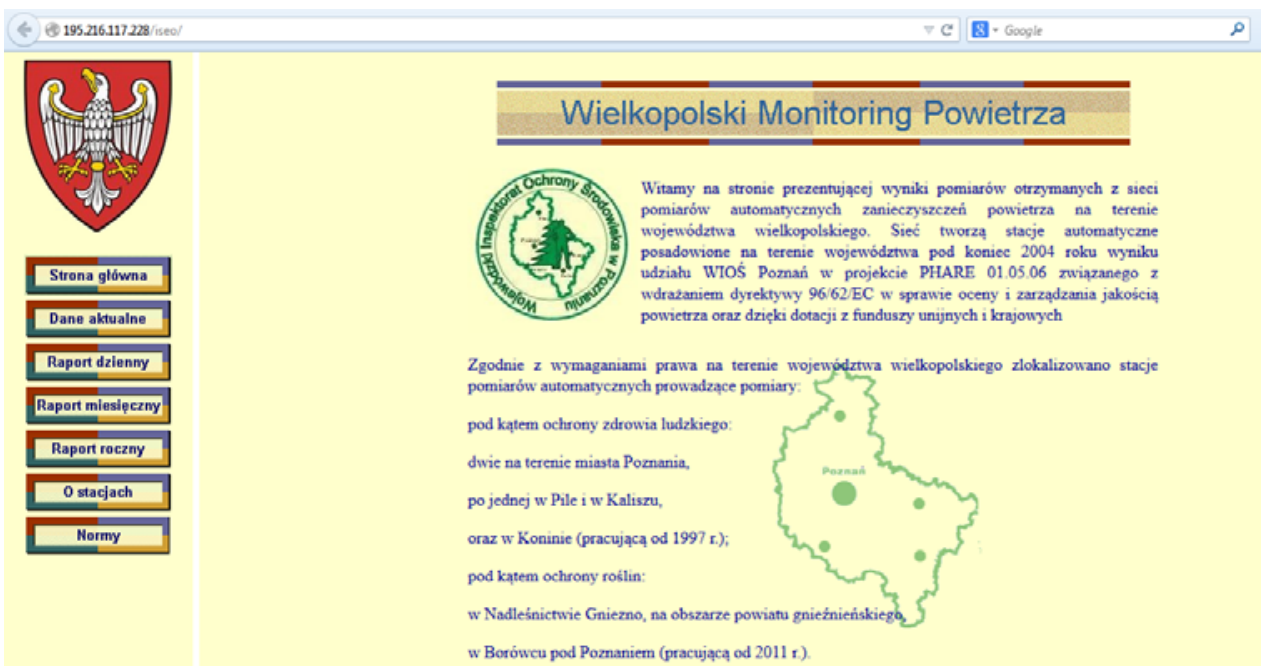

Figure 2. Main website of the Wielkopolska voivodship inspectorate for environmental protection

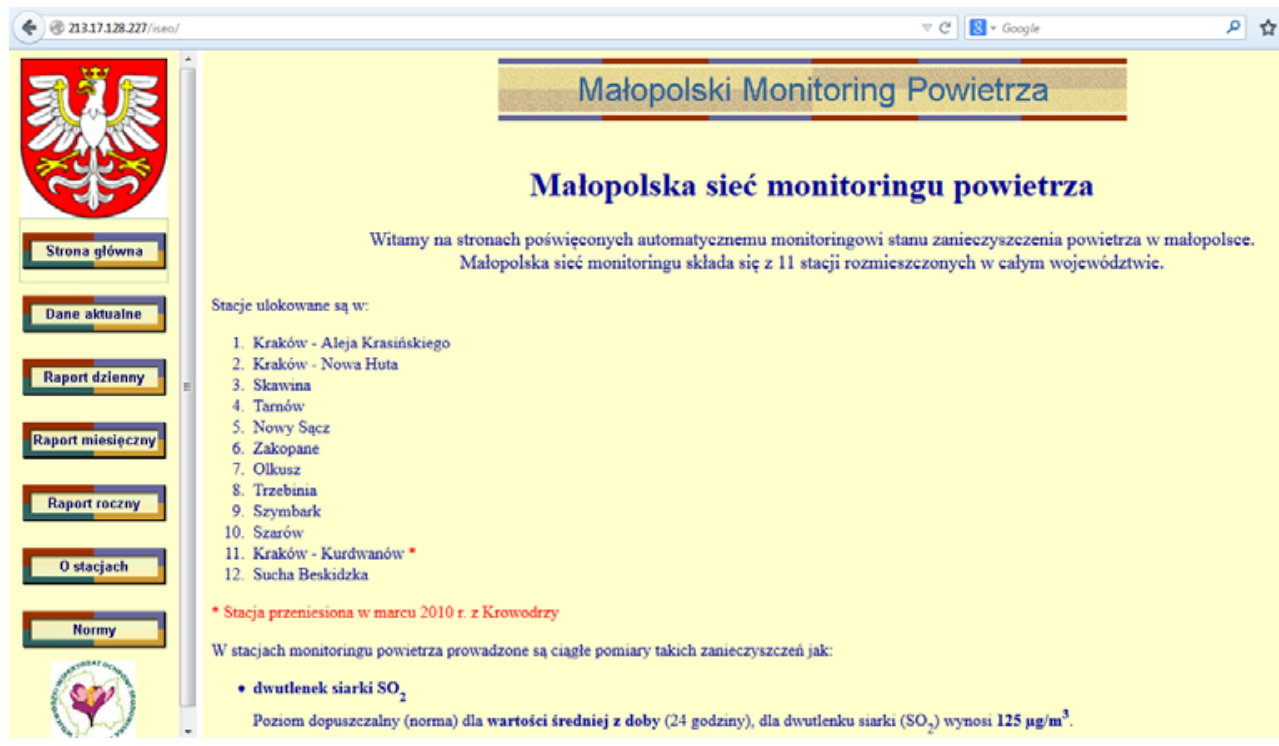

Figure 3. Main website of the Malopolska voivodship inspectorate for environmental protection

The choice of stations for which the user may view the results is made in one of the two ways: from a map or from a list. The latter is used by inspectorates in Małopolska, Wielkopolska, Łódź, Opole and Silesia. Other inspectorates use a map for this purpose. A more interactive version employs Google maps (Masovia, Pomerania, Lower Silesia 
inspectorates), other inspectorates present the map as jpg graphics where one can click on a chosen station. The map is not interactive and does not allow to change the scale, for example.

No inspectorate offers the possibility to download online data on an ongoing basis or any services connected with interoperability. The Lower Silesia inspectorate allows to download an Excel file with 24-hour mean values from automatic measurements conducted by industrial plants and manual measurements (updated monthly). The Masovia inspectorate, in turn, allows to download results of measurements from automatic stations only for 2012. Other units do not offer even such options.

The Lublin inspectorate, which started creation of a geoportal, is an important example. The portal presents a few layers on air - for example locations of measurement stations, area classification, areas for air quality assessment and data on emissions.

Information on measurement stations (e.g. station address, measured pollution, meteorological parameters) is published on websites by 14 out of 16 inspectorates. The information cannot be found only on Małopolska and Silesian inspectorates' portals. Other units present varied data on measurement stations. Some also publish photos of station surroundings. All information is presented on websites and it is not possible to download it in any format (apart from saving the webpage as HTML). Choice of location may be done from a map or from a list. Available solutions include Google maps (e.g. the Masovia inspectorate) or jpg pictures with added station locations (e.g. the Podlasie inspectorate).

Unfortunately, like in the case of monitoring data, it is not possible to download data for further processing (apart from copying it from the website in HTML). Additionally, practically each inspectorate describes measurement stations using a different set of parameters. It is difficult to see any kind of interoperability here.

This situation needs to be changed in the future. The INSPIRE Directive obliges Poland to implement various themes, among which there is Annex III.7 - Environmental Monitoring Facilities. Its description can be found in "D2.8.III. 7 Specification Data on Environmental Monitoring Facilities - Technical Guidelines” [6].

The above-mentioned document defines mandatory and optional elements of the target model of spatial data and metadata in the following areas:

- database objects including spatial objects,

- descriptive information describing the database objects, including the required IDs, etc.,

- dictionaries, code lists, etc.,

- metadata that extend the INSPIRE general profile with unique elements for environmental monitoring.

In terms of observations and measurements, the specification of environmental monitoring facilities recommends using "Guidelines for the use of Observations \& Measurements and Sensor Web Enablement-related standards in INSPIRE Annex II and III data specification development" [7]. According to this document, Observations \& Measurements and Sensor Web Enablement-related standards shall be used in INSPIRE to cover requirements in the following thematic domains:

- geology,

- oceanographic geographical features,

- atmospheric conditions and meteorological geographical features,

- environmental monitoring facilities, 
- soil.

In Poland, the Chief Inspectorate of Environmental Protection (CIEP) acts as the leading authority in environmental monitoring spatial data, understood as the location and operation of environmental monitoring devices, state of the environment and other ecosystem parameters; biodiversity, and ecological conditions of vegetation, in particular.

Application of the recommendations from [7], including the use of the SensorML standard, will enable the creation and implementation of the spatial information infrastructure node in CIEP. This should be an integrated information system (geoportal) that allows for the implementation of INSPIRE requirements and guidelines, which will be part of the State Environmental Monitoring. In addition to monitoring devices data, it should also include other spatial data resources of CIEP, including monitoring data from:

- air,

- noise,

- non-ionizing radiation - electromagnetic fields,

- surface water,

- soil chemistry, etc.

By harmonizing (with the SensorML standard) data sets representing environmental monitoring facilities of various monitoring programs, it should be possible to unify them into one coherent structure in which the following spatial object types might be available:

- devices - the location and general characteristics of environmental monitoring devices including measuring stations, sensors, sampling sites, areas of monitoring, etc.,

- $\quad$ networks - general characteristics of the measuring networks (sets of devices), resulting from the programs and methodologies of monitoring systems,

- $\quad$ programs - scopes of measurement programs for the monitoring periods together with basic information about the programs.

Through standardisation of data, the geoportal will enable the creation and use of spatial data services, including:

- searching services for data sets and spatial data services,

- viewing services for viewable spatial data,

- downloading services for spatial data (in the form of GML),

- transforming services of spatial data for the purpose of interoperability,

- services enabling invoking spatial data services.

This will allow the acquisition of information needed for discovery of different sensors, including sensor's capabilities, location and taskability. In this system, it should also be possible to add data about measuring devices operating under other monitoring programs, as well as about devices outside the State Environmental Monitoring network (e.g. from measurements carried out by scientific units). It is possible thanks to the simple model and the rich set of data types available in SensorML. Similar requirements should be met in the case of data on the results of the measurements, where the O\&M standard may be applied. By applying standards included in the SWE (SensorML, O\&M) to describe the measuring devices, it will be possible to link them to the information describing monitoring networks and to observations and measurements made.

In this context, the advantages of using the SensorML standard are:

- a good level of metadata types,

- good support for reliable processing of sensor data, 
- possibility of modelling a simple sensor or complex sensor systems,

- supporting geolocation information about sensors,

- providing accuracy information of sensors measurements,

- possibility of using the standard for various monitoring programs and their integration.

\section{Summary}

In the times of collecting and processing large amounts of information, users of data are more and more aware and demanding. They want to have access to information, be able to download, process and combine it. This is particularly true for environmental information, which in most cases is spatial data. This makes interoperability a vital aspect which should be considered when designing IT systems for spatial data infrastructures.

It is especially important now when the Chief Inspectorate of Environmental Protection is implementing the act on spatial data infrastructure in the field of "Environmental Monitoring Facilities" through standardisation and harmonisation of its resources (data and metadata) and creating a geoportal which would provide INSPIRE services: searching (CSW - Catalog Service for Web), viewing (WMS - Web Map Service) and downloading (WFS - Web Feature Service, WCS - Web Coverage Service). The use of the technologies (standards) presented in the article could be a basis for development of standards of harmonisation of NEMP and also greatly contribute to automation of data generation processes for environmental monitoring.

The article has presented an overview of IT technologies and standards that support interoperability in spatial data infrastructures. An example standard for this purpose is a component of Sensor Web Enablement - the SensorML specification. Its application for description of processes of air monitoring has been suggested. Implementation of the standard of description of measuring devices and the measurement process (from measuring the parameter to its verification and processing) would greatly facilitate combining and analysing the collected data, which is at present virtually impossible for the user.

\section{References}

[1] Act of 27 April 2001 Environmental Protection Law.

[2] Chen N., Hu C., Chen Y., Wang C., Gong J., Using SensorML to construct a geoprocessing e-Science workflow model under a sensor web environment, Computers \& Geosciences, 47, 2012, 119-129.

[3] Chen N., Wang X., Yang X., A direct registry service method for sensors and algorithms based on the process model, Computers \& Geosciences, 56, 2013, 45-55. 
[4] Compton M., Barnaghi P., Bermudez L., García-Castro R., Corcho O., Coxe S., Graybeal J., Hauswirth M., Hensonh C., Herzog A., Huang V., Janowicz K., David Kelsey W., Le Phuoc D., Lefort L., Leggieri M., Neuhaus H., Nikolov A., Page K., Passant A., Sheth A., Taylor K., Web Semantics: Science, Services and Agents on the World Wide Web, Web Semantics: Science, Services and Agents on the World Wide Web, 17, 2012, 25-32.

[5] Conover H., Berthiau G., Botts M., Goodman H.M., Li X., Lu Z., Maskey M., Regner K., Zavodsky B., Using sensor web protocols for environmental data acquisition and management, Ecological Informatics, 5, 2010, 32-41.

[6] European Commission, Data Specification on Environmental Monitoring Facilities Draft Technical Guidelines (D2.8.III.7_v3.0rc3), http://inspire.ec.europa.eu/documents/Data_Specifications/INSPIRE_DataSpecificatio n_EF_v3.0rc3.pdf (access 28.01.2015).

[7] European Commission, Guidelines for the use of Observations \& Measurements and Sensor Web Enablement-related standards in INSPIRE Annex II and III data specification development (D2.9_v2.0), http://inspire.ec.europa.eu/documents/Data_Specifications/D2.9_O\&M_Guidelines_v2 .0.pdf (access 28.01.2015).

[8] Fan M., Fan H., Chen N., Chen Z., Du W., Active on-demand service method based on event-driven architecture for geospatial data retrieval, Computers \& Geosciences, 56, 2013, 1-11.

[9] Farazi F., Maltese V., Giunchiglia F., Ivanyukovich A., A faceted ontology for a semantic geo-catalogue, The SemanicWeb: Research and Applications, 8th Extended SemanticWeb Conference, ESWC 2011 Heraklion, Crete, Greece, May 29 - June 2, 2011, Proceedings, Part II.

[10] Gaździcki J., Internetowy Leksykon Geomatyczny - Lexicon of Geomatics. (www.ptip.org.pl), 2010.

[11]Gomes de Andrade F., de Souza Baptista C., Augusto Davis Jr. C., Improving geographic information retrieval in spatial data infrastructures, Geoinformatica, 2014, DOI 10.1007/s10707-014-0202-x.

[12] Giuliani G., Ray N., Lehmann A., Grid-enabled Spatial Data Infrastructure for environmental sciences: Challenges and opportunities, Future Generation Computer Systems, 27, 2011, 292-303.

[13] IDABC, EIF - European Interoperability Framework for pan-European eGovernment services, 2004.

[14] IEEE Standard, Institute of Electrical and Electronics Engineers. IEEE Standard Computer Dictionary: A Compilation of IEEE Standard Computer Glossaries. p. 42, New York, 1990.

[15] ISA 2011 EIF - European Interoperability Framework. Towards Interoperability for European Public Services. NO-30-11-312-EN-C. European Commission, DirectorateGeneral for Informatics.

[16]ISO/IEC, Technical Draft Report, Ref. No. JTC1 SC36 WG4 N0070. Information Technology - Learning, education, and training - Management and delivery Specification and use extensions and profiles, 2003. US SC36 Secretariat.

[17] Iwaniak A., Kubik T., Ontologies in GIS and their use for construction of intelligent geoportals, Annals of Geomatics, VI, 7, 2008, 23-34. 
[18] Iwaniak A., Kubik T., Paluszyński W., Tykierko M., Kaczmarek I., Semantic based extension of search capability of SDI, Global Geospatial Conference 2012 "Spatially Enabling Government, Industry and Citizens”, Québec City, Canada, May 14-17.

[19] Iwaniak A., Łukowicz J., Strzelecki M., Kaczmarek I., Implementation aspects of an intelligent spatial information infrastructure, Annals of Geomatics, X, 4, 2012, 103117.

[20]KRI, 2012 Rozporządzenie Rady Ministrów z dnia 16 maja 2012 r. w sprawie Krajowych Ram Interoperacyjności, minimalnych wymagań dla rejestrów publicznych $i$ wymiany informacji $w$ postaci elektronicznej oraz minimalnych wymagań dla systemów teleinformatycznych (Dz. U. z 2012 r. poz. 526).

[21] Kaczmarek I., Iwaniak A., The role of thesaurus in creating semantic interoperability, Annals of Geomatics, IX, 4, 2011, 61-69.

[22] Liang $\square$ S.H.L., Croitoru A., Vincent Tao C., A distributed geospatial infrastructure for Sensor Web, Computers \& Geosciences, 31, 2005, 221-231.

[23] Lutz M., Sprado J., Klien E., Schubert C., Christ I., Overcoming semantic heterogeneity in spatial data infrastructures, Computers \& Geosciences, 35, 2009, 739752.

[24] Michalak J., Languages derived from and connected with GML, Annals of Geomatics, VI, 6, 2008, 75-84.

[25] Michalak J., UML geospatial data models and their transformation into GML schemas and database structures, Annals of Geomatics, X, 1, 2012, 15-34.

[26] Nałęcz T., The use of spatial data models and their transformation (UML, XML, GML) in geology and hydrogeology, Annals of Geomatics, IX, 4, 2011, 105-115.

[27] Prandi F., De Amicis R., Conti G., Debiasi A., Use of OGC Web Standard for a SpatioTemporal Enabled SDI for Civil Protection, Proceedings of the 17th International Conference on 3D Web Technology, New York, 2012.

[28]Rossa M., Gogołek W., Łukasiewicz A., Geostandardy, metadane i dyrektywa INSPIRE. Poradnik metodyczny Zintegrowanego Systemu Kartografii Geologicznej IKAR. Państwowy Instytut Geologiczny, Warszawa, 2009.

[29] Rossa M., Aplikacje GML dla środowiska na przyktadzie GeoSciML i GWML2 - stan aktualny, kierunki rozwoju, zastosowania praktyczne, Konferencja „GML w praktyce”, 12.04.2012, Kon-Dor, Warszawa, 2013.

[30] Rossa M., 2014a Zastosowanie języka GML do przetwarzania danych geologicznych, XXIII Szkoła eksploatacji górniczej, 24-28.02.2014, Kraków.

[31] Rossa M., 2014b Wykorzystanie języka GML do opisu danych hydrogeologicznych $i$ hydrograficznych, XXIII Szkoła eksploatacji górniczej, 24-28.02.2014, Kraków.

[32] Sánchez López T., RFID and sensor integration standards: State and future prospects, Computer Standards \& Interfaces, 33, 2011, 207-213.

Received 11.09.2014, accepted 28.05.2015 